\title{
FoFA: Diet Information for Children with Autism with Semantic Technology in Android Based Application
}

\author{
Lutfi Aristian Febrianto ${ }^{1}$, Dewi Wardani², Ardhi Wijayanto ${ }^{3}$ \\ 1,2,3 Informatics Department, Universitas Sebelas Maret, Surakarta, Indonesia
}

\begin{tabular}{l}
\hline \hline Article Info \\
\hline Article history: \\
Received August 11, 2020 \\
Revised November 11, 2020 \\
Accepted November 26, 2020 \\
Published December 30, 2020 \\
\end{tabular}

\section{Keywords:}

Android-based

Diet for autism

Mobile application

Ontology

\begin{abstract}
The number of people with autism in Indonesia increases by $0.15 \%$ or 6,900 children per year. One of the actions that can be done to overcome developmental disorders of children with autism is to do Feingold and Failsafe Diet, Specific Carbohydrate Diet (SCD diet), and Casein-Free Gluten Free diet (CFGF diet) on foodstuffs given to children with autism. There is a need for socialization and presentation of information regarding the regulation of food items given to children with autism. Currently, there is no presentation of information in the form of mobile-based applications as a forum for parents to exchange information, especially those that utilize semantic technology. By utilizing semantic technology, the Food For Autism (FoFA) application was created to share knowledge for users related to food and beverage diet menus for children with autism. The test results show that the application of FoFA can apply semantic technology related to diet and food diets for children with autism.
\end{abstract}

\section{Corresponding Author:}

Dewi Wardani,

Informatics Department, Universitas Sebelas Maret,

J1. Ir Sutami 36 A, Surakarta, Central Java, Indonesia 57126

Email: dww_ok@uns.ac.id

\section{INTRODUCTION}

Children with autism in Indonesia are estimated to increase in number [1] [2] [3]. The prevalence of autism in Indonesia increases by $0.15 \%$ or 6,900 children per year. One of the actions or efforts that can be done to overcome disorders in children with autism, namely by regulating food [4] [5] [6]. By carrying out the Feingold and Failsafe Diet, the Specific Carbohydrate Diet (SCD diet), and the Casein Free Gluten Free diet (CFGF diet) on food provided to children with autism, it can overcome developmental disorders of children with autism [7] [8] [6].

The development of the internet in Indonesia has shown a significant increase based on data from the Association of Service Providers Indonesian Internet (APJII). At the end of 2006, the number of internet users reached a figure of 25 million [9] [10]. Information about autism is just beginning to be developed, such as a few expert systems for diagnosing autism, information on the symptoms of autism, and appropriate therapy for children with autism [11] [12] [13] [14]. There is also the development of multimedia learning applications to foster the development of communication by children with autism [15] [16] [17] [18]. The era of the smartphone make web services, and program applications are easier to use by users [19] [20] [18].

The use of semantic technology allows applications to connect with various sources of information. By using semantic technology, application makers can improve their applications based on those layers of technology [21] [22] [23] [24] [5]. The use of ontology and semantic reasoners make it possible to make smarter applications that can deduce the consequences logically from the knowledge that has been considered [26] [27] [28] [29]. However, to our knowledge, semantic technology that utilized ontology directly in the android application has not been implemented yet. Even though smartphone devices already have good processing performance. Perhaps only one application has tried to implement [28]. As a new stage of technology, therefore, 
some limitations have been faced with implementing semantic technology on mobile-based applications. The number of applications is still very few. Ontology [30] [31] as the essential layer representing both data and knowledge in semantic web technology is very rarely utilized in the mobile application. The limitation of its architecture makes the utilization is more difficult compared to the utilization of web-based.

A work that has applied semantic technologies (indirect way) such as the OntoWiki Mobile Knowledge application [32] that can be used online or offline is used for data collection and uploading data from a researcher's records into the database. The Aletheia system [33] can support industrial services with heterogeneous sources of information. The beginning work in using semantic web technology on the mobile application was based on these basic concepts and architecture [34] [35] [36]. Dbpedia, which one of the prominent data set formed in semantic web technology's standard, was utilized to access through mobile application [37] [38] [39]. There is some existing research related to determining the food that should be given to children with autism [40]. Some studies have begun to utilize ontology, such as research that can display information on the nutritional content of food [41] and studies that can provide product assessments and information from various sources [34]. Unfortunately, those applications which consider the autism problem have not used semantic web technologies on mobile-based application.

Therefore, an Android-based mobile application architecture has been reviewed using semantic technology, which will then be applied in the Food For Autism (FoFA) application. The information is displayed in the form of recommendations for appropriate food and drinks for dieters in children with autism. This research aims to design architecture and build Android-based applications by applying semantic technology. The systematic writing of this research article in chapter 1 is a preliminary chapter that outlines the background of the problem, objectives, and systematic writing. In chapter 2, it is about related research that already exists. Next in chapter 3 discusses the steps or methods used to solve the study's problems: Designing mobile application architecture and implementation. Next in chapter 4 discusses the results and discussion of the research, and in chapter 5, the concluding and suggestions.

\section{METHOD}

In this method, this work will more emphasize developing a framework to implement the lower and middle layer of semantic technology, which is concerning in Ontology and SPARQL. The more challenge is how to implement it on mobile architecture, which is not yet mature comparing to web-based architecture.

\subsection{Building Ontology}

The first stage of implementation is to build the ontology. The ontology used is the ontology of diet and food menus for autism that has been built on the previous task. The ontology data extraction module by using the arc-2 library. The format JSON data which then parsed into FoFA. The ontology used in the FoFA application is FOFA.owl (in the Indonesian language) which was built earlier in 2016 [42]. It has three classes: Diet, Makanan, Minuman. It has eight object properties: bolehDimakan, bolehDiminum, bolehMakan, bolehMinum, tidakBolehDimakan, tidakBolehDiminum, tidakBolehMakan, tidakBolehMinum. It has six data properties: Deskripsi, Jenis, Nama_diet, Nama_makanan, Nama_minuman, Sumber.

\subsection{The Architecture's of Application}

The FoFA application architecture, in general, is shown in Figure 1. The architecture starts by designing the application user interface, which is used to see the appearance of the FoFA application on an android smartphone. The main features related to this research search, share and add. The search module is used to conduct searches related to food and beverage menus for dieters with autism. Furthermore, designing a sharing module that is used to share knowledge between the user (the public) and the expert user (expert doctor). The next is the add module that is used to add ontology data directly from the android interface.

Based on Figure 1 explains that the architecture of the FoFA application uses the concept of webbased android service programming. In designing this mobile application architecture using three modules, namely the search module, sharing module, and add a module. The search module is used to search for data in a database and display it on the application interface. The data will be displayed in the form of a type of diet, what foods may or may not be eaten and what drinks can be drunk or not allowed to be drunk by diets of children with autism. A user will choose the type of diet and choose what foods or drinks to look for. The sharing module is used to exchange information between users and expert users. Information exchanged is in the form of user knowledge of what foods or drinks may or may not be consumed by the diets of children with 
autism. A user enters data in the form of food or drinks and chooses the type of diet that may or may not consume the food or drink. Data sharing will be displayed on the sharing interface. The add data module is used to add data to the ontology. Data added in the form of food or drink that may or may not be consumed by diets with autism. An expert user (expert doctor) enters data in the form of food or drinks and chooses the type of diet that may or may not consume the food or drink. Then the ontology data will be loaded into the MySQL database using the load data module.

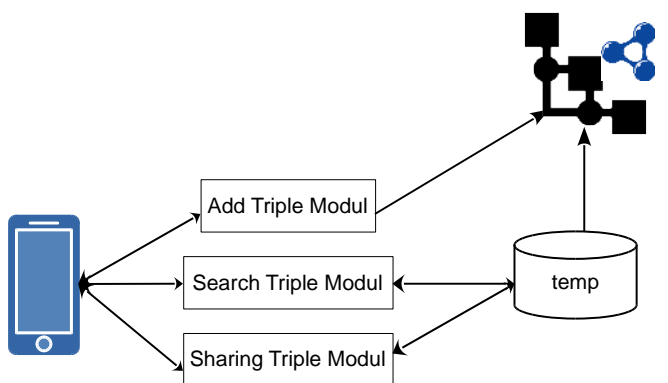

Figure 1. The Architecture of FoFA

\section{RESULTS AND DISCUSSION}

The main testing is to test the three modules: 1) Testing the diet search menu; 2) Testing knowledge sharing; 3) Testing the ontology data add. The first stage of testing the FoFA application is by testing the search module by searching food and beverage menus for diets of children with autism. An indicator of the success of the search module testing is the appearance of the food and beverage menu on the android application interface. The next test is testing the knowledge sharing module by sharing knowledge from the user to the expert user. Indicators of testing success are that users can share knowledge and applications can display knowledge sharing data on the Android interface. The next test is testing the add data module by adding ontology data which is carried out by expert users. Indicators of testing success are that the expert user has successfully added data from the android interface, and the ontology data has successfully increased.

\subsection{Experimental}

Testing begins with finding a diet menu. The diet menu looks for food that should not be eaten by carbohydrate-specific dieters. The interface search menu for foods that should not be eaten by carbohydratespecific dieters is shown in Figure 2, and Figure 3 shows the search results on foods that should not be eaten by carbohydrate-specific dieters

Testing knowledge sharing that has been done is food and beverage knowledge sharing. The food that will be shared is "nasi liwet" and potatoes. The interface for knowledge sharing is shown in Figure 4 and Figure 5. Experts will examine knowledge sharing. Before the knowledge is examined, those knowledge is stored temporarily, as shown in Figure 6. After experts examined and agree with the shared knowledge, then its added in ontology automatically, as shown in Figure 7.

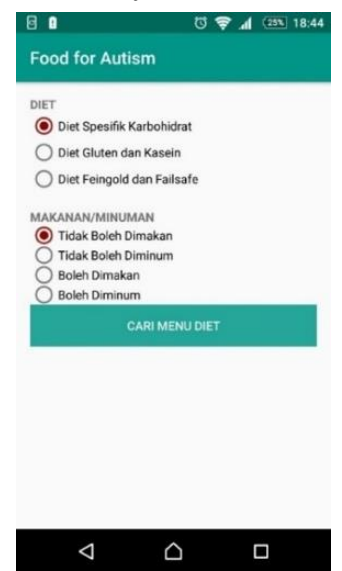

Figure 2. Display menu search interface for foods that should not be eaten by carbohydrate-specific diets

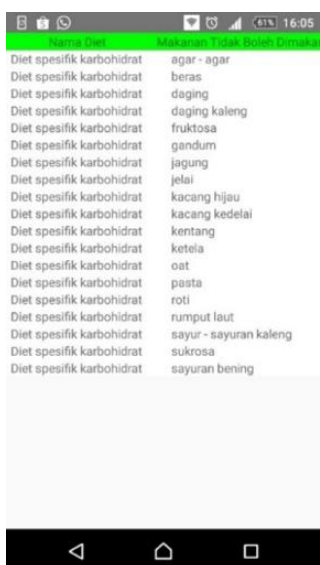

Figure 3. Display the results of a food search menu that should not be eaten by carbohydrate-specific diets 


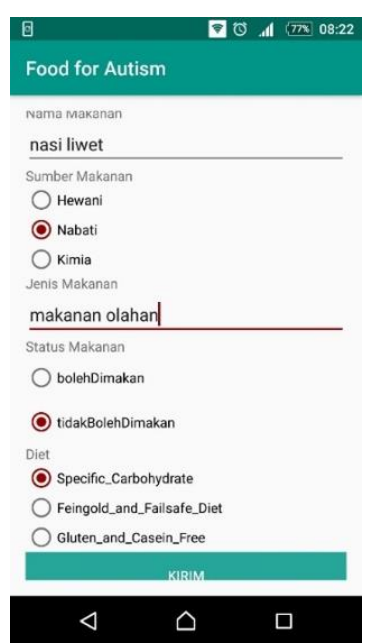

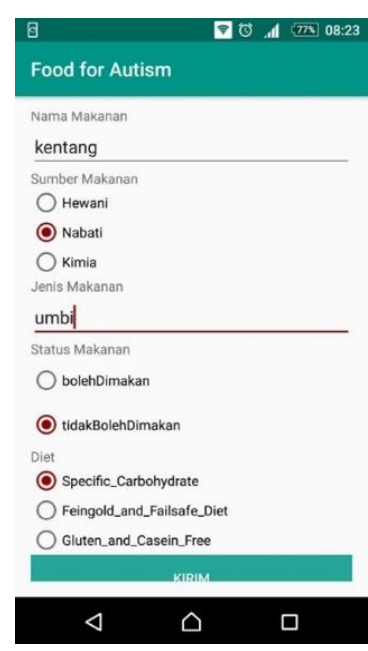

Figure 4. Display interface knowledge Figure 5. Display of potato knowledge sharing rice liwet sharing interface

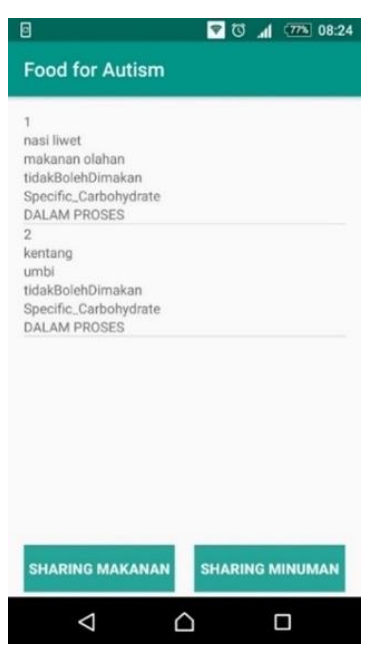

Figure 6. Display the results of sharing knowledge of liwet rice and potatoes

After experts examined and agree with the shared knowledge, then its added to the ontology. Next, the testing is to add triple knowledge into existing ontology data directly from the add data interface in the FoFA application. Adding ontology data is done by expert users. Figure 7 shows the ontology before the additional triples. Figure 8 also shows the editor loaded ontology, which does not yet add an additional triple of potatoes, oats, and plums.

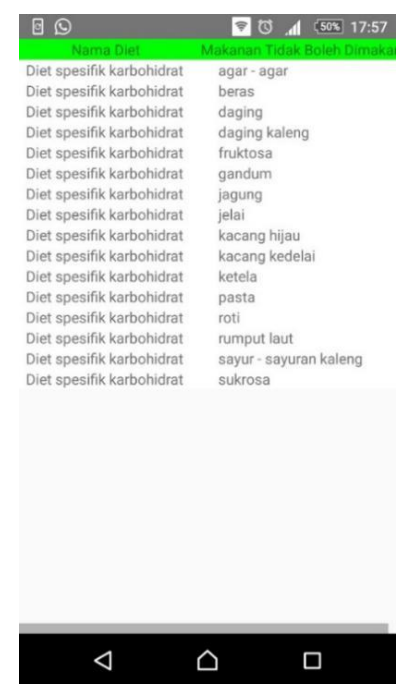

Figure 7. Display the menu list before adding the potato, oat and plum data

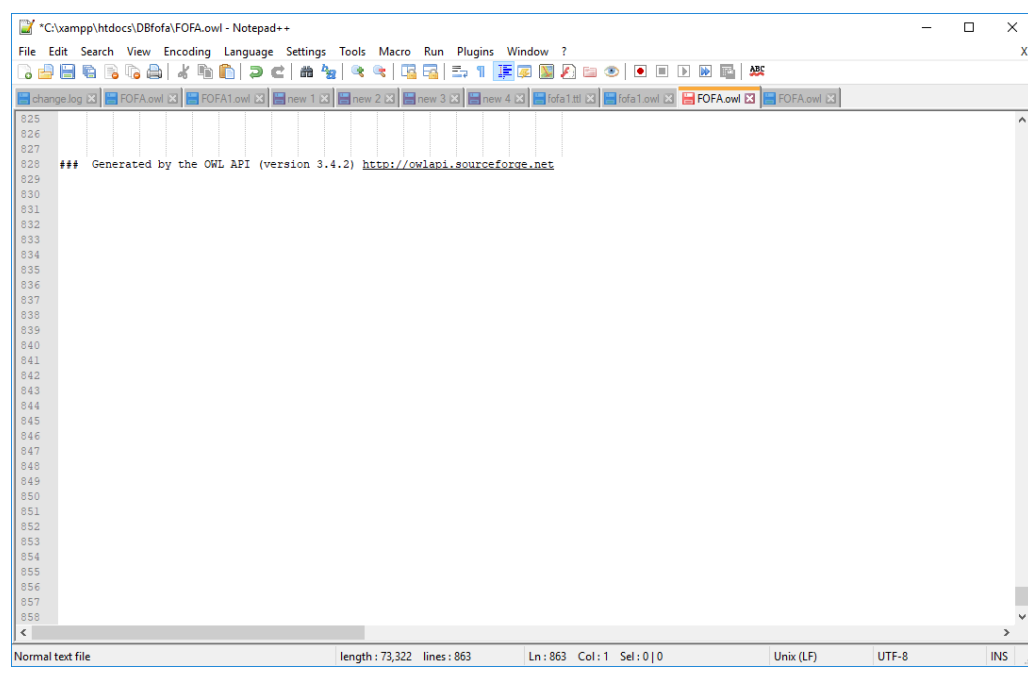

Figure 8. Display ontology data before adding data

Then, adding triple data of potatoes, oats, and plums are shown in Figures 9, 10, and Figure 11, respectively. In Figure 12, the editor of loaded ontology is also shown that the triple of potato, oat, and plum have been added. The FoFA, as shown in Figure 13, is also informed that those triples of potato, oat, and plum have been added. 


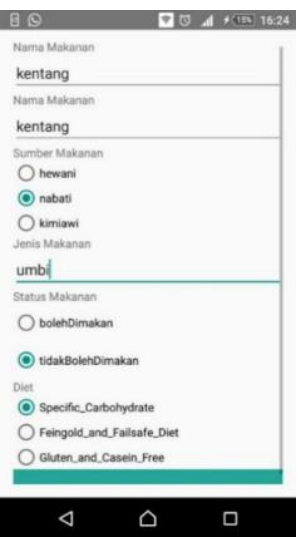

Figure 9. Display the ontology potato add data interface

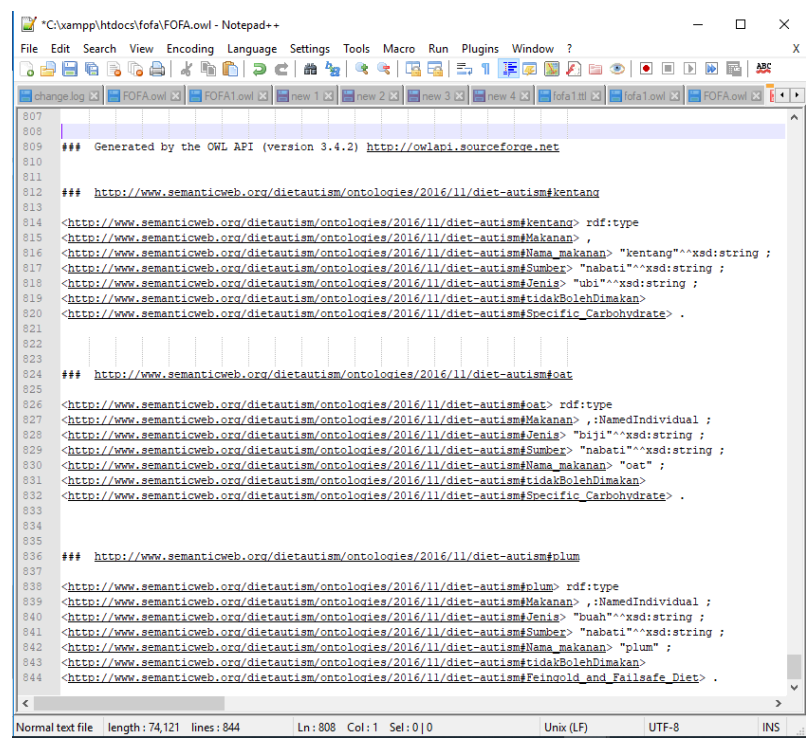

Figure 12. Ontology data display after adding data on potatoes, oats and plums

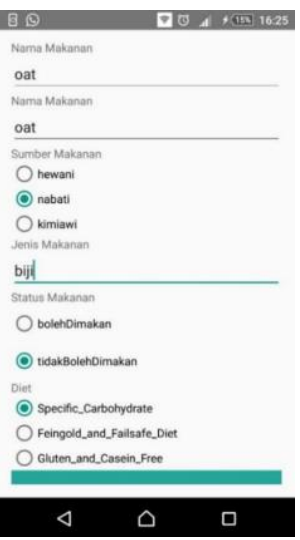

Figure 10. Display oat ontology data add interface

\section{$\triangleleft$}

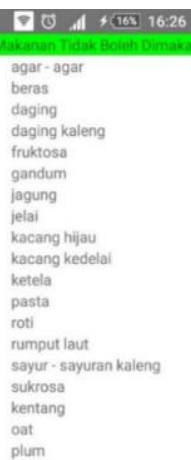

Figure 13. Display the menu list after adding the data potatoes, oats and plums

From the results of the main testing of FoFA application, it can be concluded that FoFA has implemented semantic technology. The FoFA can access ontology data and display diet menu data on the application interface; can share the knowledge that users do with expert users; and can add ontology data. The test results for the FoFA application are shown in Table 1 below.

Table 1. FoFA application test results

\begin{tabular}{ccccc}
\hline No & Feature & The Expected Result & Yes & No \\
\hline 1. & Testing looking for a & The application can access ontology and can display & $\sqrt{ }$ \\
& diet menu & a diet menu & & \\
2 & $\begin{array}{c}\text { Testing knowledge } \\
\text { sharing }\end{array}$ & Applications can share knowledge between user and & $\sqrt{ }$ & \\
3 & $\begin{array}{c}\text { expert user. } \\
\text { data } \text { ontology }\end{array}$ & The application can add ontology data & $\sqrt{ }$ \\
\hline
\end{tabular}

The main features which are related to the novelty of this work are laid in those three features, as described in Table 1. Therefore, the main testing was only for those three main features. The other features are more additional, as explained in the next part. As additional information, the FoFA application is a fully mobile application. As below a few common services which are a compliment of application FoFA. 


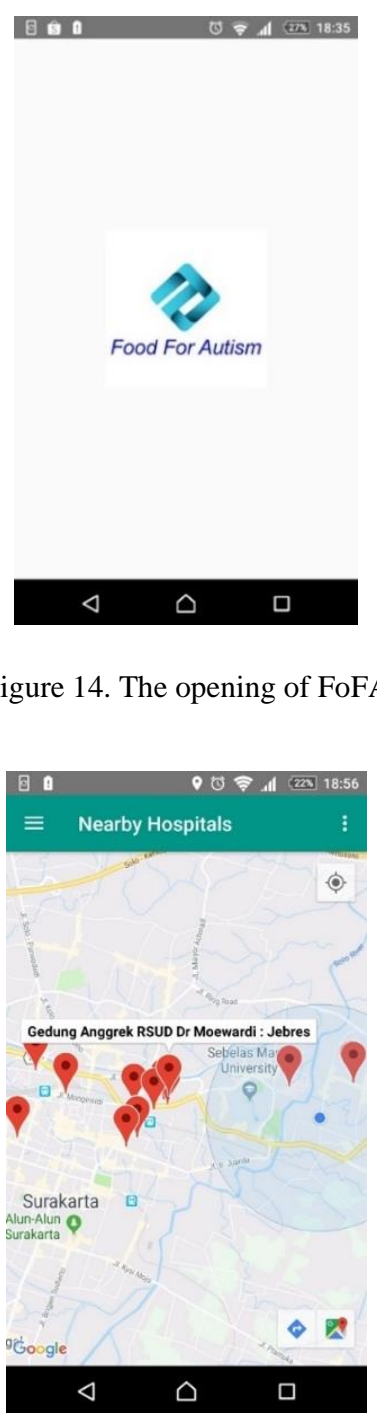

Figure 17. The interface of the

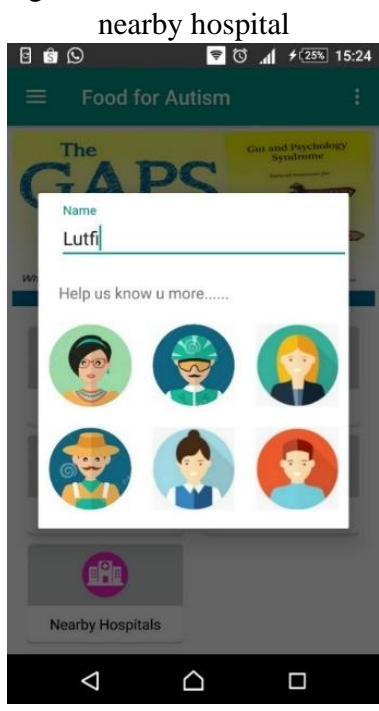

Figure 20. The interface of account setting

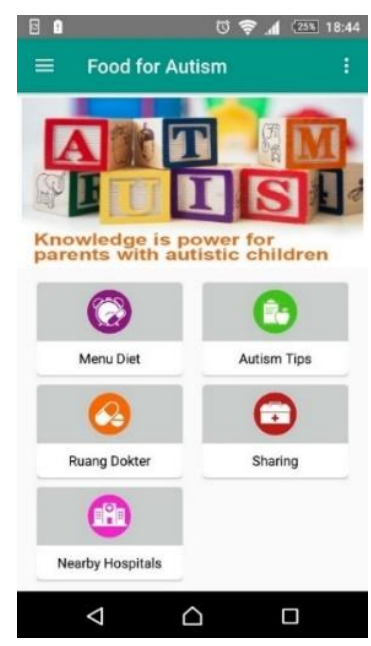

Figure 15. The interface of Home

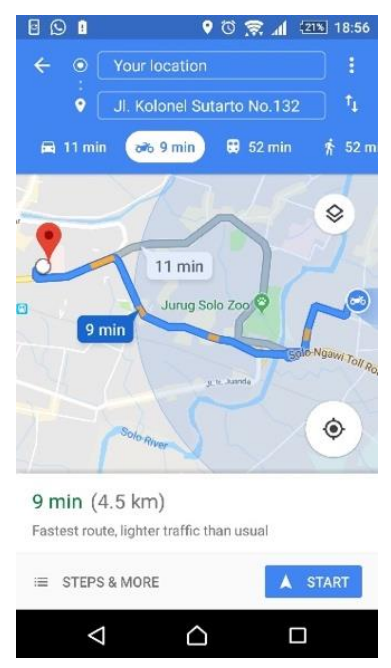

Figure 18. The interface of the route
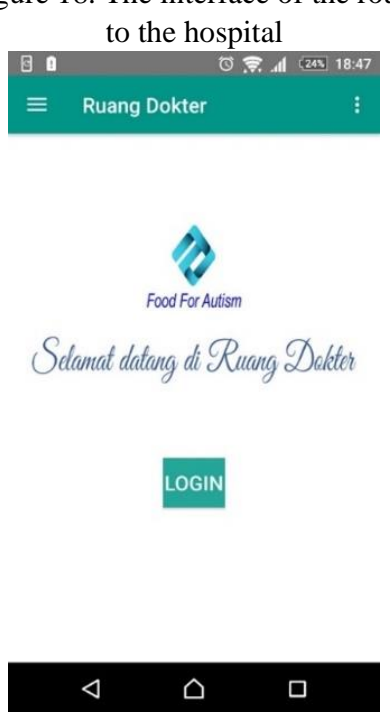

Figure 21. The interface for experts (doctor)

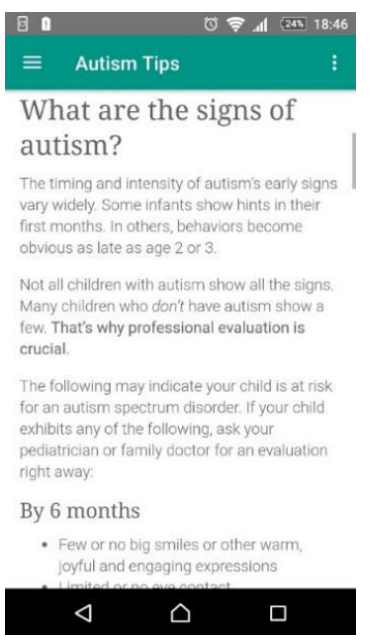

Figure 16. The interface of Search

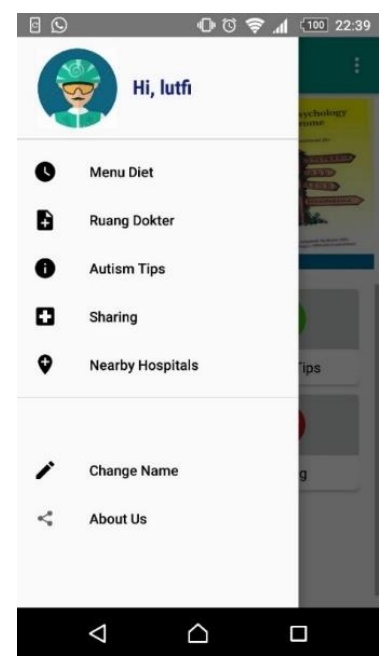

Figure 19. The interface of the toolbar menu
Login Dokter
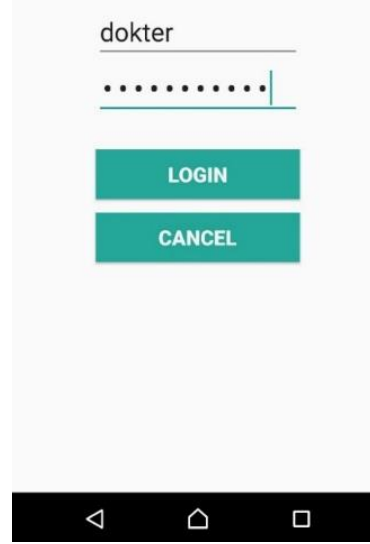

Figure 22. The interface of login for experts 
It has been deployed in the prototype with the mode which on. One doctor has utilized it as an expert, and seventeen people as the user included the author. The rating by an expert was 4 , and the average rating by the user was 4.5. The limitation is detected on the ontology, which needs to cover more knowledge.

\section{CONCLUSION AND FUTURE WORK}

This work has applied semantic technology in FoFA applications. This conclusion is supported by the results of the main application testing. It can be concluded that the application can work well and in accordance with the expected specifications. As for the details of the test results, the FoFA application has been able to access the ontology. That the FoFA application has succeeded in performing a diet search menu and successfully displaying search results on the application interface. The FoFA application has also been able to share knowledge. That the FoFA shares knowledge between the user and the expert user has successfully implemented. The FoFA application has also been able to add ontology data. That expert users have succeeded in adding diet menu data and ontology data successfully increasing. In the near future work, more complex ontology shall be provided. FoFA would be adding the other features which also utilize the semantic web technology included the better search process and improving several technical aspects.

\section{REFERENCES}

[1] T. Berney, "Autism-an evolving concept," The British Journal of Psychiatry, vol. 176, no. 1, pp. 20-25, 2000.

[2] S. Verté, H. Roeyers, and A. Buysse, "Behavioural problems, social competence and self-concept in siblings of children with autism," Child: Care, Health and Development, vol. 29, no. 3, pp. 193-205, 2003.

[3] S. Kasran, “Autisme: konsep yang sedang berkembang,” Jurnal Kedokteran Trisakti, vol. 22, no. 1, pp. 24-30, 2003.

[4] C. Newell, M. R. Bomhof, R. A. Reimer, D. S. Hittel, J. M. Rho, and J. Shearer, "Ketogenic diet modifies the gut microbiota in a murine model of autism spectrum disorder," Molecular autism, vol. 7, no. 1, p. 37, 2016.

[5] D. N. Ruskin et al., "Ketogenic diet improves core symptoms of autism in BTBR mice," PLoS One, vol. 8, no. 6, p. e65021, 2013.

[6] G. A. D. Kusumayanti, "Pentingnya pengaturan makanan bagi anak autis," Jurnal ilmu gizi, vol. 2, no. 1, 2011.

[7] J. H. Elder, M. Shankar, J. Shuster, D. Theriaque, S. Burns, and L. Sherrill, "The gluten-free, casein-free diet in autism: results of a preliminary double blind clinical trial," Journal of autism and developmental disorders, vol. 36, no. 3, pp. 413-420, 2006.

[8] P. Whiteley, J. Rodgers, D. Savery, and P. Shattock, "A gluten-free diet as an intervention for autism and associated spectrum disorders: preliminary findings," autism, vol. 3, no. 1, pp. 45-65, 1999.

[9] E. de Argaez, "Internet world stats news," Retrieved December, vol. 15, p. 2009, 2006.

[10] J. D. Boss, C. Marcjan, and F. Su, Distributed internet user experience monitoring system. Google Patents, 2000.

[11] P. Lialiou, D. Zikos, and J. Mantas, "Development and evaluation of an expert system for the diagnosis of child autism.," Studies in health technology and informatics, vol. 180, pp. 1185-1187, 2012.

[12] I. M. Nasser, M. Al-Shawwa, and S. S. Abu-Naser, "Artificial Neural Network for Diagnose Autism Spectrum Disorder," 2019.

[13] N. R. M. Isa, M. Yusoff, N. E. Khalid, N. Tahir, and A. W. binti Nikmat, "Autism severity level detection using fuzzy expert system," in 2014 IEEE International Symposium on Robotics and Manufacturing Automation (ROMA), 2014, pp. 218-223.

[14] D. Aprilia, A. Johar, and P. Hartuti, "Sistem pakar diagnosa autisme pada anak," Rekursif: Jurnal Informatika, vol. 2, no. 2, 2014.

[15] O. Grynszpan, P. L. Weiss, F. Perez-Diaz, and E. Gal, "Innovative technology-based interventions for autism spectrum disorders: a meta-analysis," Autism, vol. 18, no. 4, pp. 346-361, 2014.

[16] S. L. Odom et al., "Technology-aided interventions and instruction for adolescents with autism spectrum disorder," Journal of autism and developmental disorders, vol. 45, no. 12, pp. 3805-3819, 2015.

[17] V. Knight, B. R. McKissick, and A. Saunders, "A review of technology-based interventions to teach academic skills to students with autism spectrum disorder," Journal of autism and developmental disorders, vol. 43, no. 11, pp. 2628-2648, 2013.

[18] R. Kurniawan, A. Mahtarami, and T. P. Lestari, "Aplikasi multimedia pembelajaran metode PECS (picture exchange communication system) untuk membantu perkembangan komunikasi dan interaksi anak autis," Jurnal Cybermatika, vol. 3, no. 2, 2016.

[19] G. Alonso, F. Casati, H. Kuno, and V. Machiraju, Web services. Springer, 2004.

[20] K. Gottschalk, S. Graham, H. Kreger, and J. Snell, "Introduction to web services architecture," IBM systems Journal, vol. 41, no. 2, pp. 170-177, 2002. 
[21] D. W. Wardani and S. H. Yustianti, "An Ontology of Indonesian Ethnomedicine," in 2014 International Conference on Information, Communication Technology and System, Oct. 2014, pp. 47-52.

[22] D. W. Wardani, "Semantic Commerce for Developing Country," IJID (International Journal on Informatics for Development), vol. 1, no. 1, pp. 17-25, 2014.

[23] L. Cabral, J. Domingue, E. Motta, T. Payne, and F. Hakimpour, "Approaches to semantic web services: an overview and comparisons," in The semantic web: Research and applications, Springer, 2004, pp. 225-239.

[24] T. Berners-Lee, J. Hendler, O. Lassila, and others, "The semantic web," Scientific american, vol. 284, no. 5, pp. 28 $37,2001$.

[25] T. Gruber, Where the Social Web Meets the Semantic Web. 2006.

[26] B. Berendt, A. Hotho, and G. Stumme, "Towards semantic web mining," in International semantic web conference, 2002, pp. 264-278.

[27] N. Bassiliades, G. Antoniou, and I. Vlahavas, "A defeasible logic reasoner for the semantic web," Rules and Rule Markup Languages for the Semantic Web, pp. 49-64, 2004.

[28] R. Yus, C. Bobed, G. Esteban, F. Bobillo, and E. Mena, "Android goes Semantic: DL Reasoners on Smartphones.," in Ore, 2013, pp. 46-52.

[29] S. Ilarri, E. Mena, A. Sheth, and others, "Semantics in location-based services," IEEE Internet Computing, vol. 15, no. 6, p. 10, 2011.

[30] R. Arp, B. Smith, and A. D. Spear, Building ontologies with basic formal ontology. Mit Press, 2015.

[31] N. Guarino, D. Oberle, and S. Staab, "What Is an Ontology?," in Handbook on Ontologies, S. Staab and R. Studer, Eds. Springer Berlin Heidelberg, 2009, pp. 1-17.

[32] T. Ermilov and S. Auer, "Enabling Linked Data Access to the Internet of Things," in Proceedings of International Conference on Information Integration and Web-based Applications, Services, New York, NY, USA, 2013, p. 300:300-300:308, doi: 10.1145/2539150.2539157.

[33] M. Aleksy and B. Stieger, "Supporting service processes with semantic mobile applications," in Proceedings of the 8th International Conference on Advances in Mobile Computing and Multimedia, 2010, pp. 167-172.

[34] D. Zamula and M. Kolchin, "MneMojno-Design and deployment of a Semantic web service and a mobile application," in 14th Conference of Open Innovation Association FRUCT, 2013, pp. 171-176.

[35] A. Zeeshan, A. Chimay, R. Darshan, C. Patricia, and others, "Semantic web based services for intelligent mobile construction collaboration," Journal of Information Technology in Construction (ITcon), vol. 9, no. 26, pp. 367379, 2004.

[36] W. Van Woensel, S. Casteleyn, and O. De Troyer, "A framework for decentralized, context-aware mobile applications using semantic web technology," in OTM Confederated International Conferences" On the Move to Meaningful Internet Systems", 2009, pp. 88-97.

[37] C. Becker and C. Bizer, "DBpedia Mobile: A Location-Enabled Linked Data Browser.," Ldow, vol. 369, p. 2008, 2008.

[38] C. Becker and C. Bizer, "DBpedia mobile-a location-aware semantic web client," Proceedings of the semantic web challenge, pp. 13-16, 2008.

[39] C. Becker and C. Bizer, "Exploring the geospatial semantic web with dbpedia mobile," Journal of Web Semantics, vol. 7, no. 4, pp. 278-286, 2009.

[40] M. A. Suarez and K. M. Crinion, "Food choices of children with autism spectrum disorders," International Journal of School Health, vol. 2, no. 3, pp. 1-5, 2015.

[41] C. Snae and M. Bruckner, "FOODS: a food-oriented ontology-driven system," in 2008 2nd IEEE International Conference on Digital Ecosystems and Technologies, 2008, pp. 168-176.

[42] D. E. Cahyani, A. Prabanuadhi, R. I. Irfan, and L. A. Febrianto, "Ontology Model for Dietary of Children with Autism Spectrum Disorders," Journal of Telecommunication, Electronic and Computer Engineering (JTEC), vol. 10, no. 2-4, pp. 129-132, 2018. 